\title{
Transfer of Learning as a specific case of transition between learning contexts in a French work-integrated learning programme
}

\author{
Laurent Veillard, UMR ICAR (CNRS, University of Lyon) \\ laurent.veillard@univ-lyon2.fr
}

This paper is a pre-version of an article published in Vocations \& Learning, 2012, vol. 5, issue 3, pp. 251-276

\begin{abstract}
The aim of this article is to discuss transfer of learning in a tertiary technical course in the French educational context. The focus is on a pedagogical sequence (i.e. a complex problem-solving activity) requiring different types of knowledge that students are expected to have learnt previously in the different parts of their training course (both at university and in the workplace). The theoretical approach considers transfer of learning as a complex transition, including not only cognitive but also social and identity changes. This type of transition can be more or less difficult according to the types of knowledge and the pedagogical organisation of the training course, including more or less connective activities between its different components. We recorded two groups of students during the pedagogical sequence and analysed their collective activity during the problem solving. Our findings show that students can easily transfer concrete knowledge from the workplace whereas they have great difficulty in using theoretical concepts and methods coming from the academic teachings at the university. We propose an interpretation of the students' difficulties by analysing the characteristics of these different social learning contexts. We also discuss the way in which such types of connective activities can be designed and managed by teachers to improve their efficiency.
\end{abstract}

Keywords: transfer of learning, tertiary education, work-integrated learning, boundary crossing, connectivity, transition between learning contexts,

\section{Introduction}

A belief in transfer lies at the heart of our educational system. Most educators want learning activities to have positive effects that extend beyond the exact conditions of initial learning. They are hopeful that students will show evidence of transfer in a variety of situations; for example, from one problem to another within a course; from one course to another; from one school year to the next; and from their years in school to their years in the workplace. (Bransford \& Schwartz, 1999, p. 61)

This belief in transfer is likely to be widely shared amongst communities of teachers and trainers in the initial vocational education and training systems across many countries. Over recent years, a range of pedagogical innovations have been enacted to diversify the learning situations in these systems. In addition to the traditional academic lectures, exercises and workshop activities, we can often find a diversity of innovations for learning situations within training courses including games, computer simulations, visits to companies, short or long internships in one or more firms, cooperative programmes alternating periods at school and in the workplace. In many instances, students face a succession of learning experiences, yet the settings where they occur remain quite distinct from each other for students. These learners are supposed to be able to gather and integrate these different experiences often without any help (even a little) when building complex skills and competencies and then transferring them to work-related activities (i.e. on the job). At the same time, many vocational teachers and trainers have found that transfer of learning between different academic disciplines or from school to the workplace is often difficult for students to realise. Numerous studies in 
psychology of diverse theoretical perspectives confirm that such transfer is a difficult cognitive process for people when left alone to complete this task without support (Bransford \& Schwartz, 1999; Detterman \& Sternberg, 1993). Consequently, knowledge and skills learned at school are often under-utilised in the workplace. Yet, globalisation, technical and economic evolutions are leading to more complex working environments, requiring workers to be innovative and able to make connections between different communities of practice (other enterprises, educational institutions, research centres, libraries, etc.) (Engeström, 1987). In this paper, we discuss a specific teaching sequence dedicated to the transfer and integration of learning (Veillard \& Coppé, 2009) in a tertiary sandwich course (alternation of study periods at the university and work periods in a company) in the field of industrial logistics and quality management. We aim to characterise learners' abilities and difficulties in using different types of knowledge in a different social context than those where they initially learned them and to explore hypotheses which may explain the students' capacities to transfer. Our goal also is to analyse what role particular artefacts, people (i.e. teachers or trainers) and the pedagogical organisation play in improving this transfer process. Initially, we briefly review the existing literature on transfer of learning to identify key precepts and premises. Some new theoretical and methodological perspectives have emerged in the last decade that offer renewed possibilities to understand this perennial problematic in a new perspective, more adapted to real contexts. From this review of existing literature, we next present our own theoretical and methodological framework used to study the teaching sequence described above. Following this, the empirical findings are presented and then some possible interpretative hypotheses are explored. The next section is dedicated to an analysis of some possible actions by teachers to assist students in this difficult process. In the conclusion, we discuss the theoretical contribution of our work and its practical implications for the teacher training programme and the pedagogical organisation of VET courses.

\section{Shifting to a broader conception of transfer}

Transfer of learning became an object of research at the beginning of the $20^{\text {th }}$ century. Thorndike and his colleagues were among the first to test, over several years, individuals' ability to use previously learnt knowledge in new situations (Thorndike \& Woodworth, 1901). Numerous studies have been undertaken since then, within different theoretical perspectives (e.g. behaviourism, cognitivism, situated cognition) but most of the time by using a type of methodology which has remained more or less the same since Thorndike and Woodworth's first experiments. That is, participants are given an initial problem or task and are trained to solve it correctly. Then, they receive a second problem, apparently different from the first one, but which has the same logical structure and can be solved by analogy from the learning associated with the first problem. Yet, transfer is a difficult cognitive process (Baldwin \& Ford, 1988; Detterman \& Sternberg, 1993; Frenay, 2004; Singley \& Anderson, 1989). Cases of success are mostly limited to near transfer, i.e. between situations that are identical except for a few important differences whereas far transfer (i.e. where the tasks are distinct) is much rarer. However, there are some possibilities to improve transfer of learning significantly including: enhancing initial learning; learning experiences focused on conceptual understanding instead of simply fixed procedures; concrete and various examples where the same knowledge is used; and training in reflexivity and metacognition. These strategies, however, have a limited effect and the reality of transfer is often analysed with generous criteria (Detterman, 1993). Individuals' difficulties are not explainable in unitary ways nor consistently across theoretical orientations. Cognitivists have traditionally based their interpretation on people's ability to recognise the same logical structure behind problems which are different on the surface (e.g., different stories). This ability depends on the 
construction of a previous mental schema fitting into this logical structure (Reed, 1996). Yet, seemingly, people tend to favour surface features instead of formal patterns. Situated approaches criticise this dissociated view of knowledge from social contexts.

Its central characteristics include separation of cognition from social world, the separation of form and content implied in the practice of investigating isomorphic problem solving, and a strictly cognitive explanation for continuity in activity across situations. All these dissociate cognition from its contexts, and help to account for the absence of theorizing about experiments as social situations and cognition as socially situated activity. (Lave, 1988, p. 43)

In real life, most of the time people probably do not transfer abstract knowledge from one situation to another, but rather exercise an ability to interact with things and people: a practice rather than a cognitive schema. Experiments on transfer are too often focused on problems where symbolic representations play a major role. This type of transfer exists, but is not common because it is complex on the cognitive plane (i.e. highly demanding). That is perhaps why the transfer rate is so low in most of these experiments. Following and elaborating on ideas developed initially by Gibson in the field of psychology of perception (1979), some authors (e.g. Greeno, Smith, \& Moore, 1993) suggest that most of the time the environment is directly perceived through affordances, without the mediation of any symbolic representation. Affordances are defined as supports for particular activities creating relevant properties of things and materials in a given situation.

If a learned practice is to transfer, it has to be learned in a form that is invariant across changes in the situation or that can be transformed as needed, and transfer depends on ability to perceive the affordances for the activity that are in the changed situation. The activities that people learn are constructed and situated socially. To a great extent, the affordances that enable our activities are properties of artefacts that have been designed so those activities can be supported. The functions of theses properties as affordances are shaped by social practices. People learn these practices, including the utilities of affordances mainly by participating in them along with other people (Greeno, et al., 1993, p. 104)

Consequently, from this perspective, improving transfer requires learning not only how to solve problems by using abstract knowledge, but also how to participate in social practices and to identify the different situations where these practices are useful. Affordances, perception and recognition are central to the learning approach. The situated cognition account is of interest here because it acknowledges not only cognitive but also social and environmental factors that have a strong influence on the transfer of learning. But this theoretical approach shares with cognitivism (and even with behaviourism) a similar focus on the role of invariant elements in the transfer process. In all these theories, transfer remains fundamentally a question of identifying common elements of static contexts. The difference is whether they are in physical situations, cognitive tasks, or social practices. However, some recent research studies challenge this epistemological stance. For instance, Bransford and Schwartz (1999) consider that transfer is often difficult to achieve because it is conceptualised and measured in too narrow ways. Instead, the problem with traditional approaches to transfer is more particularly a dominant methodology which studies transfer occurring only during a single and final transfer task, with "sequestered problem solving", i.e. subjects in experiments who have no opportunities to seek help from other external resources such as texts or colleagues. Instead of this quite closed conception, these authors propose shifting the focus 
onto how previous learning may modify subsequent learning capacity. To do this, it is necessary to explore individual's ability to learn new knowledge and relate their learning to previous experiences and thus to go beyond the moments of a source and a target experimental task.

Other authors, like Beach, question whether the transfer metaphor, which refers to the "appearance of a person carrying the product of learning from one task, problem, situation or institution to another" (Beach, 1999, p. 101) is any longer relevant. This metaphor, originally linked to Platonism and Cartesian philosophy, is strongly anchored in many of the precepts and premises of our education systems and reflects an ideological position which is dominant, especially in American society (but probably also in a lot of western countries): "a functionalist epistemology in which progress is marked by adaptation to and acceptance of existing social conditions" (p. 103). The metaphor of transfer is held by Beach to be an epistemological obstacle to better understanding people's transitions across the boundaries of different forms of social organisation, like schools, workplaces, or home life. Thus, he suggests reconceptualising transfer by using the concepts of generalisation and consequential transition. Generalisation here is defined as: "the continuity and transformation of knowledge, skill and identity across various forms of social organisation". It is not found in the individual agent or in static situations, but in the changing relationship between individuals and activities. It involves multiple interrelated processes (social, cognitive, identity, emotional, etc.) rather than a single cognitive procedure and cannot happen without artefacts (symbols, technologies, texts, etc.). The generalisation process occurs during consequential transitions, involving a developmental change in the relation between an individual and one or more social activities. Transitions are consequential when they are subject to conscious reflection. Beach suggests there are potentially different types of consequential transitions. He proposes a distinction between lateral, collateral, encompassing and meditational transitions. The first two involve persons moving between pre-existing social activities: in a single direction when the transition is lateral (e.g. a student becoming a professional after a training course); with simultaneous participations in two or more social activities in the case of collateral transitions. Encompassing and mediational transitions have persons moving within the boundaries of a single activity or into the creation of a new activity (see Beach, 1999, p114-119 for a definition of each type). Each type can be found in VET systems and potentially involves the construction or transformation of knowledge, identities and skills, rather than the single application of something that has been acquired elsewhere, without any changes.

Studies of transfer of learning from a Cultural and Historical Activity Theory (CHAT) perspective also try to reconceptualise it (Konkola, Tuomi-Gröhn, Lambert, \& Ludvigsen, 2007; Tuomi-Grohn \& Engeström, 2003). In this theoretical orientation, learning and transfer are studied as social processes existing within and between activity systems such as schools and work teams. Under the pressure of internal and external factors, these social organisations are constantly changing, facing contradictions, new problems and challenges and not only routine tasks. More and more, changing social and technical conditions are requiring a horizontal type of expertise (i.e. not only vertical); that is, people able to go beyond the boundaries of an activity system to look for new solutions used elsewhere (e.g. methods, technology, human resources) and to introduce them. But generally, this boundary crossing activity (Engeström, Engeström, \& Kärkkäinen, 1995) is complex for individuals, especially because a new tool or a new practice coming from another activity system cannot be introduced without interpretative and adaptation processes. These can be achieved much better at a collective level, it is claimed, when two activity systems (e.g. a school and a workplace in the case of VET students) share this common preoccupation. CHAT researchers call this boundary crossing activity developmental transfer. 
Other researchers in the field of vocational education argue for changing the pedagogical organisation of the vocational training systems in favour of more connectivity to help students transfer and integrate the various knowledge they have already learnt (Senström \& Tynjälä, 2010; Griffiths \& Guile, 2003). In professional training programmes, the segmentation into different academic discipline contents and the separation of theory and practical components over time and space can work against their transfer and integration (Eraut, 2004). This is a key concern because numerous studies show that expertise consists of integrated elements of different types of knowledge (theoretical, practical, etc.) (Bereiter, 2002; Pastré, 2008; Samurçay \& Rabardel, 2004). Some of these forms of knowledge can only probably be learned at school and others only by participating in workplace activities (Billett, 1994; Eraut, 2004). Consequently, the development of expertise requires more integrative pedagogies, helping students to connect their different learning experiences at school and in the workplace (Griffiths \& Guile, 2003; Nielsen, 2009; Tynjälä, 2009; Volanen, 2009). A closer engagement between educational institutions and workplaces may therefore become necessary to develop some new mediating tools and activities. These might include: reflexive thinking and writing about work; connective curriculum articulating learning at school and in the workplace; interdisciplinary and collective projects in partnership with workplaces, tutoring, mentoring, etc. solving practical and complex problems is also probably a key activity in the knowledge transfer and integration process (Bereiter \& Scardamalia, 1993; Leinhard, McCarthy Young, \& Merriman, 1995). This engagement can be a powerful way to learn the theoretical concepts, methods or tools which can be useful in specific situations and also how to use them to solve practical problems (often including modifications or adaptations). Certainly, problem solving in concrete settings offers the possibility of converting academic knowledge (i.e. declarative concepts) into complex skills and situated and pragmatic knowledge, which are key components of expertise (Bereiter \& Scardamalia, 1993; Pastré, 2008).

\section{Theoretical framework}

In this paper, we choose to conceptualise transfer within a more general theoretical framework of situated learning in VET systems which are increasingly using a range of learning experiences. In these types of programmes, students frequently have to make consequential transitions of different types: lateral, collateral, encompassing and mediational (Beach, 1999). Amongst these, collateral transitions refer to students' movements between different yet relatively simultaneously situated social activities (e.g. academic disciplines and interdisciplinary teachings at school, workplace learning, reflexive activities when going back to school, and so on). Transfer of learning refers to cases of collateral transitions in which the students attempt, either on their own, or in response to a someone else's request (a teacher for instance), to adapt some knowledge or skills they have acquired in a previous social context to another setting. Transfer of learning requires not only cognitive operations but also some other possible interrelated types of processes, e.g. social, emotional and identity processes. This theoretical stance leads us to a broader investigation of what is usually undertaken in the classical approaches of transfer. Our hypothesis is that the characteristics of the different contexts of student activity in VET systems must be carefully studied for three main reasons.

Firstly, we need to better understand what learning opportunities existed for the students in their previous contexts before assessing whether or not transfer of learning occurs in a new context. Curriculums and educators' discourse about students' learning must be considered carefully. There is often a gap between what is planned in curriculums or what teachers or supervisors can say about students' learning and what they really learn. Learning opportunities arise from participation in activities within specific social contexts. Many 
studies demonstrate that technical and social organisations have an important impact on these learning opportunities (Billett, 2001; Fuller, Hodkinson, Hodkinson, \& Unwin, 2005). The sociology of knowledge, for instance, provides concepts that assist this analysis. The concepts of classification and frame (Bernstein, 1996; Hughes \& Moore, 1999) are used for these purposes. Classification refers to the division of knowledge into categories (of discourse, practice or social roles). Frame characterises the method of accessing that knowledge which is often under the control of certain people or institutional rules. Depending on the context, weak or strong classification and frame can lead to very different learning environments. Generally, a strong classification in an institution leads to a weak connectivity between the different learning contexts.

Secondly, knowledge has a culturally situated meaning and a pragmatic value in its initial context of use and learning (Billett, 2001; Lave \& Wenger, 1991). We must know this social and pragmatic meaning for the students to understand the type and the importance of the processes of change they have to make between the different contexts. Transfer of learning often implies some confrontation between specific identities related to the different contexts (Tanggaard, 2008). For instance, it may make little sense for students in workintegrated learning programmes to reconsider some successful vocational tasks at school in a more analytic way. Their motivation for such educational activity may be low.

Thirdly, ways of accessing knowledge may need to be modified to suit a new context and sometimes this context itself must be changed. For instance, a stock calculation method is generally used through a general and rigorous procedure in an academic context. In the workplace, some particularities can lead to using the same method in a more qualitative way, without necessarily respecting all the theoretical conditions. In this case, the aim can be to get a rough idea of level of the company's stock. This type of modification is often too difficult for novices to succeed on their own: i.e. it is a transfer that is 'too far'. Tools and human players can play a greater role in the transition and must be analysed as such. "Boundary objects" are specific material or symbolic objects that can play a very important role in transfer of learning because they "have different meanings in different social worlds but their structure is common enough to more than one world to make them recognizable, a means of translation." (Star \& Griesemer, 1989, p. 393) Similarly, some people (who we call "boundary spanners" or brokers in the authors' words) can give valued help to novices because of their knowledge of different institutions or situations, their interpersonal networks and their ability to speak different "languages" (Buxton, Carlone, \& Carlone, 2005; Koskinen, 2008; Wenger, 1998). And, finally, the pedagogical organisation of the training course may have been designed to develop connectivity between different learning contexts, with different activities (such as with complex problem solving) and tools to help students during the transition processes to transfer and integrate the different types of knowledge. On the other hand, this problematic may have been ignored by the designers and the students have to manage these difficult processes by themselves.

In this paper, we are specifically interested in problem solving activities as a way to promote and support transfer and integration of knowledge. We selected and studied a complex problem solving activity in a tertiary course which requires using, modifying and integrating several types of knowledge learned previously in different contexts (i.e. both concepts and methods from different academic teachings and knowledge learned during workplace periods). A first set of research questions were used to focus on what is expected by the teacher who manages this pedagogical activity: what are the types of knowledge the teacher expects from the students during the problem solving? From which previous learning contexts should they come? What knowledge modifications need to be made during the transition between the different contexts? A second set of questions were used to focus on the knowledge used by the students during the problem solving. What are the types of knowledge 
that they really proposed and used during the problem solving? What are their difficulties? A third type of questioning is about the possible reasons for these difficulties. Is it possible to explain them by the learning conditions in previous contexts and the modifications required for the transition to the new context? Are there any tools which can hold a boundary object function? How does the teacher help the students during the transition process? More generally, is the pedagogical organisation of the training course favourable to knowledge transfer and integration? How is it possible to improve the efficiency of this sequence?

\section{Methodology}

\section{General context of the pedagogical situation}

The study was conducted in a two year tertiary course (bachelor degree) in the field of industrial logistics and quality management. Students are apprentices ${ }^{1}$ and alternate teaching periods at university and on-the-job learning periods in a company fortnightly. In the workplace, each apprentice is guided on a daily basis by a workplace supervisor, generally the department manager. Apprentices also have university trainers who are responsible for checking if the student's learning conditions are good and for helping the workplace supervisor to assess the young novices according to specific university criteria. The global objective of this undergraduate programme is to train middle-level managers able to address logistics and quality tasks and problems in industrial firms, from both the technical and human point of view. In Table 1 below, the titles of the different Teaching Units (TU) during the first and the second years are listed.

\begin{tabular}{|l|l|}
\hline Number and name of the Teaching Unit First year & Second year \\
\hline 1: algebra - Statistics & $17:$ algebra - operational research \\
2: calculus & 18 vocational English language \\
3: communication & 19: information systems - databases \\
4: economics - law & $20:$ human relationships and vocational communication \\
5: general English language & (part 2) \\
6: basic principles of automatics & $21:$ concepts and tools for production management \\
7: basic principles of accounting & 22: industrial improvement \\
8: basic principles of mechanics & 23: project management (part 2) \\
9: introduction to computer sciences & 24: industrial project \\
10: manufacturing data and processes & 25: advanced accounting \\
11: basic principles of quality management & 28: computer assisted production management \\
12: industrial logistics & $30:$ programming (part 2) \\
13: study of the different production systems & 31: advanced accounting techniques \\
14: stock and supplies management & $32:$ tools for quality management \\
15: shop floor control & $41:$ environment in production management \\
16: manufacturing planning (middle course) & workplace periods debriefing \\
20: human relationships and vocational communication (part & Personal and professional project \\
1) & Sport \\
23: project management (part 1) & \\
30: programming (part 1) & \\
Sport & \\
\hline
\end{tabular}

Table 1 - Titles of the different academic discipline Teaching Units during the two years

The pedagogical situation the study focuses on is scheduled to occur at the end of the second year of the students' study program. We have chosen it because it meets the criteria defined in

\footnotetext{
${ }^{1}$ Apprenticeship programmes were extended to tertiary level in 1987 in France. Since this time, apprenticeship has been a possible juridical and pedagogical mode of initial training at all education levels (from worker to engineer and manager). This route is more and more popular in France, because the school-to-work transition is easier. However, most tertiary training programmes are still schoolbased.
} 
our research questions: students do not have to learn new concepts or methods, but must solve a long and complex open problem by using and articulating different knowledge taught and/or learned previously in the different academic discipline TUs or in the workplace. This pedagogical sequence was designed several years ago by an experienced teacher who was concerned about the lack of connectivity between the different learning contexts of the training programmes. He concluded something was missing between the different TU and the practicum periods in the workplace for the students to be able to develop complex competencies.

The pedagogical sequence lasts thirty-two hours and is part of TU 22, called "industrial improvement" (cf. table 1). The problem involves designing the information system of a virtual company (SME) to allow good manufacturing conditions. The sequence is subdivided into three steps. First, the students have to define collectively (i.e. all the class) the organisational structure of the company, i.e. the functional roles of the different departments and their hierarchical relationships (4 hours). At the end of this first part, the class is divided into small groups of two, three or four students. Each group then plays the role of one specific department. The next step is the longest ( 20 hours). The departments have to analyse the information they need to exchange between them to allow them to function correctly and to produce a good collective performance (e.g. goods quality, delivery time, productivity and so on). The students have to create both paper formats and procedures for designing the information system. During the last step (8 hours), an instructional game (i.e. simulation of an industrial production) is used to test the efficiency of the information system.

The pedagogical sequence is enacted during two or four hour sessions. According to the step, students all work together or in small groups. The students are supposed to have a large degree of autonomy to decide how to solve the problem. The teacher's role is to introduce the aims and the organisation of the sequence, to give advice and stimulate the use of previous knowledge and to validate intermediary results at the different steps of the problem solving.

\section{Data collection and analysis}

The research reported here focuses only on the first step of the problem, corresponding to the first two class sessions of two hours each, when students have to collectively define the organisational structure of the company. First, we undertook an a priori analysis, focusing on the different types of resources to be used for solving this first part of the problem. We tried to infer the initial contexts of use of these different resources and the kind of transitions the students have to make to transfer them to the sequence. This a priori analysis was principally undertaken from information supplied by the teacher who designed this sequence and from pedagogical documents such as those presenting the teaching situation to the students, the course books related to different TU where the students were supposed to learn relevant resources for the problem and student productions during the same sequence but from previous years. Then, we video-recorded two batches of students in 2004 and $2005^{2}$. Our aim was to analyse possible variations in student activity according to two different groups. We also wished to study more particularly how the teacher adapts his interventions according to the changing behaviour of the group of students. We used two cameras and three wireless microphones to capture what was occurring on both sides of the class and editing software to mix the two videos. Some additional data were also gathered to complete our research corpus: the teacher's and the students' written productions during the two sessions and students' reports on their company's organisation.

\footnotetext{
${ }^{2}$ There were 24 students in 2004 and 16 in 2005.
} 
The video recordings were analysed in different steps. First, we constructed a detailed synopsis of each class session (see Table 2). The first three columns give, respectively, the time, the problem solving step and the social organisation of the class. The next two are for a synthetic description of the teacher's and students' activity and verbalisations. The last column is dedicated to the classification of the types of knowledge (see below). We were not interested in a detailed transcription of the verbalisations and gestures because our aim was to focus on the problem solving process and the knowledge and meanings shared between the participants. Sometimes we used the narrative mode (ex: "St10 suggests noting the different functions on the board") to summarise parts containing few ideas. But we mainly made a synthetic transcription focusing on arguments and knowledge without other characteristics like prosody, hesitation, repetition, etc. This synopsis allowed us to have both an overview of the problem solving during the two sessions and to analyse the different symbolic resources used for that purpose.

\begin{tabular}{|c|c|c|c|c|c|}
\hline $\begin{array}{l}\text { Time } \\
(\mathrm{mn})\end{array}$ & Step & Organisation & Teacher (Te) & Students (Sts) & $\begin{array}{l}\text { Type } \\
\text { of K }\end{array}$ \\
\hline \multirow[t]{9}{*}{$32^{\prime}$} & \multirow[t]{9}{*}{$\begin{array}{l}\text { Defining } \\
\text { the } \\
\text { different } \\
\text { functions }\end{array}$} & \multirow[t]{9}{*}{$\begin{array}{l}\text { St10 } \\
\text { standing } \\
\text { near the } \\
\text { board } \\
\text { Te sitting } \\
\text { near St23. }\end{array}$} & $\begin{array}{l}\text { Te: - The aim of this first } \\
\text { session is to get a first draft of } \\
\text { the functional structure of the } \\
\text { company. And I want to stress } \\
\text { this particular point: use a } \\
\text { functional approach. }\end{array}$ & & K1 K2 \\
\hline & & & & $\begin{array}{l}\text { - St10 suggests noting the different functions on } \\
\text { the board. Several other students : yeah (St10 } \\
\text { stands-up and goes to the board) }\end{array}$ & $\mathrm{K} 1$ \\
\hline & & & & - St9 proposes to have a brainstorm. & K2 \\
\hline & & & & $\begin{array}{l}\text { - St10: I suggest we list all the functions and after, } \\
\text { we will select the ones we want to keep. }\end{array}$ & K1 \\
\hline & & & & $\begin{array}{l}\text { Students' propositions (F writes each proposition } \\
\text { on the board) : } \\
\text { - St } 20 \text { : manufacturing }\end{array}$ & K3 \\
\hline & & & & - ST8: purchasing-supplying & K3 \\
\hline & & & & - St3: scheduling-planning & K3 \\
\hline & & & & $\begin{array}{l}\text { - St21: you should separate scheduling and } \\
\text { planning }\end{array}$ & K3 \\
\hline & & & & - St3: no scheduling and planning, that's similar & K3 \\
\hline
\end{tabular}

Table 2: extract from a detailed synopsis (first session, 2004 batch)

For a detailed analysis, we built a categorisation of the different types of knowledge used by the students and the teacher during the problem solving (see Table 3). There are different ways to describe and classify knowledge. Several researchers have proposed particular kinds of knowledge categorisation, sometimes very general, sometimes restricted to specific vocational domains. These categorisations are based on various criteria: general cognitive structures (Anderson, 1983; Schank \& Abelson, 1977; Simon \& Chase, 1973); epistemological distinctions (Eraut, 2004; Shulman, 1986); socio-cultural uses or categories (Nonaka \& Takeuchi, 1995 ; Rosch, 1977; Scribner, 1985), etc. For this research, we decided to build a categorisation based on two pertinent criteria according to our problematic (c.f. Table 2). The first one refers to the learning context where the different types of knowledge were supposed to be used/learned by the students for the first time. For instance, K2 refers to some kinds of knowledge taught in different teaching units, whereas $\mathrm{K} 3$ is learned in the workplace. $\mathrm{K} 1$ and $\mathrm{K} 5$ are specific to the context of the problem solving activity. $\mathrm{K} 4$ is both linked to some previous learning contexts and to the Turbix sequence. The second criterion is more epistemological and allows us to distinguish between theoretical knowledge (K2), 
knowledge of concrete organisations (K3), methodological knowledge (K1), knowledge of a specific case (K4) and pedagogical knowledge.

\begin{tabular}{|l|l|l|l|l|}
\hline K1 & K2 & K3 & K4 & K5 \\
\hline $\begin{array}{l}\text { Problem solving strategy } \\
\text { goal(s) / sub-goals; types } \\
\text { of resources to use } \\
\text { depending on the } \\
\text { problems; way of } \\
\begin{array}{l}\text { articulating these } \\
\text { resources) }\end{array}\end{array}$ & $\begin{array}{l}\text { Academic } \\
\text { concepts, } \\
\text { methods and } \\
\text { tools }\end{array}$ & $\begin{array}{l}\text { Concrete } \\
\text { organisations of } \\
\text { some companies } \\
\text { (ex: HR } \\
\text { Department) }\end{array}$ & $\begin{array}{l}\text { Characteristics of } \\
\text { the Turbix virtual } \\
\text { company (ex: } \\
\text { manuf. goods, nb } \\
\text { of employees) }\end{array}$ & $\begin{array}{l}\text { Pedagogical } \\
\text { organisation of the } \\
\text { teaching sequence }\end{array}$ \\
& & & \\
\hline
\end{tabular}

Table 3: categorisation of the different types of knowledge

This analysis allowed us to quantify, step by step and overall, the types of knowledge used both mainly and more rarely by the students (and also by the teacher when he decides to interact with them). The last column of Table 2 gives some examples of our categorisation process, which was created both from the successive ideas expressed by the actors during the sessions and from different documents giving information about the students' previous social contexts. For instance, we chose to categorise K3 when one student (St20) said "manufacturing", because, in this case (it was not always possible) we had the possibility to check that there was a department named "manufacturing" in his company. We gleaned this information from a work experience written during his first year of the training. Additionally, some selected parts were transcribed (e.g. verbalisations and gestures) for a deeper analysis of the way students use the different types of resources. We were particularly interested in students' difficulties or abilities to manage the different types of knowledge. We tried to interpret them by analysing the collateral transitions required between the initial context of use/learning and this specific situation. As for the categorisation process, we based our interpretation both on video episodes and different documents giving information about the students' previous social contexts. For example, we carefully studied students' reports written during the first practicum period, insofar as they gave us some information about the kind of tasks they carried out in the workplace and the organisational context of these tasks. We undertook the same type of analysis for each academic discipline, both from textbooks and short interviews with the teachers. Furthermore, we attempted to assess the support given both by some possible boundary objects and the teacher in the transitions between the different contexts.

\section{A priori analysis}

During the first part of the global sequence, students have to build the organisational structure of a virtual company. They are expected to know the main industrial characteristics of this firm (called Turbix), because the latter is the virtual context of a simulation about production management the students have already played twice before. This activity allows learners to simulate the production of mechanical parts in an SME firm. Each participant (or group of participants) plays a specific functional role (ex: manufacturing department, supply department, stock management department, etc.). The first time the students engaged with this simulation was at the very beginning of the training programme. It was used to introduce them to the specific issues of production management. They engaged with it for the second time at the end of the first year of their studies when they were supposed to apply different methods to manage the production process correctly. In our case, the simulation is only used at the end of the pedagogical sequence, to test the information system designed by the 
students. Previously, only the virtual context of this simulation (the Turbix company) was used and the students had to remember its main characteristics. Ideally, the problem solving requires the students to use and combine three ways of modelling firms' organisation: a business process approach; a business function analysis and an analysis in terms of field of responsibilities (Lorino, 1995). First, all the necessary functions required for an effective production process has to be defined. For this first task, the students are strongly urged by the teacher to use what they know about the organisation of their company.

Excerpt 1: the students' workplace experiences (interview with the teacher designer of the teaching sequence)

"An interesting point is that, at this time, they have significant workplace experience in an industrial firm and more particularly they know the key functions in the production process: planning, production management etc. especially as I asked them [previously in another TU] to write a small study about the decisional process for the production management in their company so they have already worked on their firm's organisation and they know it a little bit"

But just proposing a list of functions from concrete organisations is not enough. The students also have to check whether all the necessary functions have been listed. The best way to do that is to model the global production process as successive technical activities starting from a customer's order and ending with the product delivery. Once this has been done, students can check if all activities can be carried out by the functions listed previously. If any activities remain, this means that some functions are lacking. If some functions are not related to any activities, their usefulness is disproved and they must be removed. The last step is allocating the different functions to a limited number of departments and establishing the functional and hierarchical links between them. The final outcome must be a flow chart.

Concepts and methods related to these three approaches had been taught previously in different academic teaching units. The functional approach is a small part of a stock management teaching unit, which is situated at the very beginning of the first year. Before introducing the concepts and methods related to stock management, the teacher of this module explained basic concepts about what constitutes an organisation.

Excerpt 2: definition of function and department (textbook of the stock management teaching unit)

"We saw previously that a company aims to transform raw materials into goods or needs into services. This is possible through a set of functions, which are distributed differently according to the size of a company.

3.1 notion of function: functions are described by action verbs characterising a specific action of production (designing; supplying; production management; 3.2 notions of department and hierarchical organisation: refer to the internal organisation of a company, which allows the realisation of the different functions [...] According to the type of organisation, boundaries between department are more or less defined. "

The concept of business process is defined in another teaching unit, called Quality Management. This unit is scheduled in the middle of the second year. The teacher in charge of the module explained theoretically what a business process is when he introduced the main differences between the 1994 and 2000 versions of the ISO 9001 norms: in the 2001 version, it is necessary to describe an organisation through different business processes. The students had to deal with this concept again later in the unit, during practical work. The teacher asked them to design a business process by using specific computer software. 


\section{The types of knowledge used during the problem solving}

Tables 4 and 5 presnt the main results for the categorisation of the different types of knowledge used by the students and the teacher during the two class sessions.

\begin{tabular}{|l|l|l|l|l|l|l|l|}
\cline { 3 - 8 } \multicolumn{2}{c|}{} & \multicolumn{7}{|c|}{ Types of knowledge } \\
\cline { 2 - 8 } \multicolumn{2}{c|}{} & K1 & K2 & K3 & K4 & K5 & Total \\
\hline \multirow{3}{*}{ Teacher } & $\mathrm{n}$ & 67 & 68 & 84 & 48 & 101 & 368 \\
\cline { 2 - 8 } & $\%$ & 18.2 & 18.5 & 22.8 & 13 & 27 & 100 \\
\hline \multirow{3}{*}{ Students } & $\mathrm{n}$ & 38 & 53 & 415 & 38 & 81 & 625 \\
\cline { 2 - 8 } & $\%$ & 6 & 8.5 & 66.4 & 6.1 & 13 & 100 \\
\hline
\end{tabular}

Table 4: Batch 2004

\begin{tabular}{|l|l|l|l|l|l|l|l|}
\cline { 3 - 8 } \multicolumn{2}{c|}{} & \multicolumn{7}{|c|}{ Types of knowledge } \\
\cline { 3 - 8 } \multicolumn{2}{c|}{} & K1 & K2 & K3 & K4 & K5 & Total \\
\hline \multirow{3}{*}{ Teacher } & $\mathrm{n}$ & 47 & 42 & 69 & 28 & 51 & 237 \\
\cline { 2 - 8 } & $\%$ & 19.8 & 17.7 & 29.1 & 11.8 & 22 & 100 \\
\hline \multirow{3}{*}{ Students } & $\mathrm{n}$ & 128 & 165 & 358 & 20 & 36 & 707 \\
\cline { 2 - 8 } & $\%$ & 18.1 & 23.3 & 50.6 & 2.9 & 5.1 & 100 \\
\hline
\end{tabular}

Table 5: Batch 2005

These findings highlight the fact that students both from batches 2004 and 2005 frequently used knowledge about the organisation of companies (K3=66.4\% in 2004 and 50.6 in 2005). By linking what they stated in their previous written reports, it appears that this type of knowledge is specific to each of their workplaces. The transcripts of some excerpts show that, most of the time, they proposed names of organisational entities (e.g. logistics, manufacturing, finance, engineering etc.) and discussed them without really distinguishing between the different concepts of department, function and even sometimes, jobs (e.g. electrician, warehouse worker). Then, they had great difficulty in agreeing on the meaning of each word. It was hard to decide precisely what the content of each of these organisational entities could be, because, depending on the companies, the same functions are not always allocated to the same departments. Anyway, everyone defended their own particular organisation and the debates were lively as seen in Excerpt 3.

Excerpt 3: defining what a logistics department is (Batch 2004 - Session 1 $0 \mathrm{~h} 41 \mathrm{~m} 10 \mathrm{~s}$ ) (the Students (St.) are numbered in alphabetical order)

- St2: logistics first / ((St2 writes logistics on the board))

- St12: what do you mean by logistics / ((St2 turns towards St12))

- St20: go on tell us

- St2>St12: logistics means receiving shipment and storage of goods

- St1: tell us why /

- S18: yeah say why / [...]

- St1: it's a small company that's why it is not useful to separate too much 
- St23: yes but logistics could be also shipment

- St9: yes receiving, shipment and storage of goods

- St14: logistics could also mean planning scheduling ((St2 turns towards St14))

- St23: no that's production management, it's part of production management

- St1: yes but logistics that's too global

- St23: scheduling is part of logistics too

- St1: yes it's an SME he told us it's an SME

- St23: it could also be part of the production management department

- St9: yes it's an SME it's part of the production management department not warehousing

There were similar debates later in the session and during the next session, for example about the aims of a manufacturing department. In 2005, the students also had similar exchanges, especially about the meaning of logistics (Session $1-0 \mathrm{~h} 58 \mathrm{mn} 30 \mathrm{~s}$ ). Whilst students frequently used what they knew about parts of their company's organisation, our results show that both in 2004 and 2005, they did not use much the first (K1, problem solving strategy), the second (K2, concepts, methods or tools) and the fourth (K4, characteristics of the virtual company) types of knowledge. Although they had already encountered this virtual company twice before, students had forgotten its main characteristics. They asked the teacher several times to remind them of information about the Turbix company, for instance the number of employees or the types of manufactured goods. In 2004, the students spontaneously chose to use the brainstorming method to start the problem solving. But, after this first step, which led to an unsatisfying solution for the teacher, they did not suggest many methods or tools any more $(\mathrm{K} 2=8.5 \%)$. Instead, they applied the teacher's suggestions without really debating the strategy $(\mathrm{K} 1=6 \%)$. In 2005 , there were far more debates about the right strategy to choose $(\mathrm{K} 1=18.3 \%)$ and the way to use methods or define concepts $(\mathrm{K} 2=23.3 \%)$. But none of these debates led to an efficient way of designing the organisation. Students proposed several methods: modelling the order-delivery business process (session $1-0 \mathrm{~h} 30 \mathrm{mn}$; process session 2 - 0h42mn); using the SADT systemic approach (session 1 - 0h54mn; session 2 - 0h16mn); using a brainstorming method (session $2-0 \mathrm{~h} 28 \mathrm{mn}$ ). But the group had great difficulty in using them efficiently. Lastly, let us say a few words about the K5 category (i.e. pedagogical knowledge). Both in 2004 and 2005, the students did not use this type of resource frequently, except for getting details about the pedagogical organisation of the sequence (e.g.: assessment modalities of their work; method of setting up the small work groups; etc.). The teacher gave much of this type of information at the beginning of the first session and the students mainly asked for details (more in 2004 than in 2005) after his initial introduction.

\section{Interpretation of the students' activity}

We can summarise our findings as follows. All the students easily suggested parts of their company's organisation and they did it with great enthusiasm, trying to convince the others that their organisation was the best. It also seemed easy for them to use the brainstorming method. On the other hand, few suggested more complex methods and all had great difficulty in defining a strategy and applying these symbolic resources to this particular problem. Articulating several methods and concepts seemed to be particularly difficult for the students. These findings can be interpreted by linking what the students were able or not to do during these two class sessions with both the characteristics of their previous social contexts of learning and the types of transition needed to move between them. 


\section{Learning about the organisation of companies in the workplace}

The students' reports provide us with some information about their workplaces as learning contexts. Most students were engaged in practicum in operational departments like logistics, manufacturing, supplying-shipping, warehousing, etc. They learnt by participating in the regular activities of these departments, frequently by doing daily technical tasks (e.g.: manufacturing scheduling; stock management) or other more innovative work (e.g.: managing the $5 \mathrm{~S}$ method in the warehouse, analysing and improving the manufacturing flows within a workshop, etc.). All these tasks seldom exceeded the limits of their department and did not require analysing and questioning the firm's organisation. Therefore, the organisation of a company gained - not surprisingly - only a practical meaning for most of the students, that is, an unproblematic and unchanging local context for the action rather than something which must be analysed and modified. Moreover, the conceptual tools, which are required to analyse an organisation (e.g. functional, business process models, etc.), remain theoretical and almost invisible in a lot of companies especially in Small to Medium sized Enterprises (SME). All students inthe two batches were located in an organisational chart, but rarely in a process or a function. Their supervisors were in charge of some aspect of operational management, i.e. people positioned in a department and visible on the organisational chart. The business process model was even less discernible for a young novice because it integrated activities led by members of various departments where the students had no opportunities to go. So, we can conclude that the social division of work and the classification and frame of the knowledge were probably great enough in many workplaces to limit the students' learning opportunities in terms of understanding the different organisational structures of companies and gaining skills in modelling and transforming them. Moreover, the fact that this was their first work experience strengthened the students' tendencies to consider the organisational structure of their company as the only one possible (with only minor variations depending on the size of the firm), and to try to convince the others to choose this type of organisational chart.

Transferring knowledge from the workplace was part of a consequential transition made by the students, including both cognitive and identity processes. Our hypothesis is that each student was strongly engaged in an identity construction process within the workplace. That is, they used the organisational particularities of their companies as a resource to define and differentiate themselves in relation to the other students during this pedagogical sequence, as shown in excerpt 5 below.

Excerpt 5 - This is like that in some companies (batch 2004 - Session $1-1 \mathrm{~h} 17 \mathrm{~m} 24 \mathrm{~s}$ )

St23>St24: in the design department they know about norms etc.

St24: yeah but they have to certify the parts .. there'll be certification for the parts

St23: yes but they already know that they don't perform quality management tasks

St24: yes they do

St18: yes but before the parts have to go through the quality department

St23: no they don't . people already know that

St18: when you design something new

St23: yes they [design department] have some idea of the norms

St18: yes but they must contact this department [quality management] to check if these parts fit the quality standards and to get their consent

St23: yes but this is in the engineering process department

St18: no this is not only in the engineering process 
St23: personally I think it's that so I can't convince you .. it's like that in some companies perhaps in your company people have to do it another way that's all

In this excerpt, we can see that both cognitive and identity dimensions are closely related in the students argumentation and make the outcome of the debate very difficult.

Conceptual learning in the academic discipline courses

As the above a priori analysis indicates, the most important concepts for problem solving were taught separately in different teaching units. This separation is difficult for the students as each of these conceptual notions were used in a different context and for a different purpose than in the interdisciplinary sequence. Understandings about function and department were taught one and a half years previously, in the stock management teaching unit. In this context, they were prerequisite knowledge for the teacher who needed to introduce them to explain different stock management methods in more detail. They were not used as tools for analysing, designing or modifying company organisation. In this case, the students faced two cumulative difficulties: both remembering the contents of a long past teaching course and using concepts learned during this teaching for a very different purpose. The business process model was a small part of the quality management teaching unit delivered in the midterm of the second year. This teaching is not too far off, but the difficulty in this particular transition relies on the changing meaning between the two contexts. Students probably had great difficulty in imagining how the business process approach could be used for something other than quality management projects, for instance: in this case, designing a new organisation and a new information system. We must suggest a last possible reason for the students' difficulties. As the learning programme lasts two years, it is not implausible that students just forget some knowledge, or never learned it at all when it was taught in a TU. The videorecordings offer some data showing that students remember quite well the name of the different methods and concepts while not necessarily remembering what those names mean.

Our discussions with the different teachers in charge of the various academic teaching units show that none of them were particularly aware of the difficulties of transfer of learning. We showed them some video recording excerpts and they were very surprised at the students' difficulty in using what they considered well-known basic concepts (especially the distinction between the notions of function, business process and department). After viewing these video clips, they claim to have become a bit more aware that the curriculum and the pedagogical organisation offered little connectivity between the different academic discipline courses. Indeed, the classification of knowledge is well established and quite strong between the different academic courses. The different concepts, methods or tools are taught according to the specificities of each discipline (i.e. specific frame), and, most of the time with one end in mind. Moreover, if some teachers try to connect their teaching with practical situations in the workplace, they don't do this in an interdisciplinary manner. The teachers also realised that none of the teaching units really allows a deep study of the key concepts of this sequence (that is, function, business process and department). They lacked pedagogical coordination because they only used the official curriculum to coordinate their teachings and this was not enough to really ensure that the students have all the required knowledge for this problem solving activity. The existing pedagogical organisation does not help students to face complex problems. They have no real situations in which to learn more strategic knowledge (i.e. how to select and combine different concepts and methods). This pedagogical sequence is the first time students have had to face such a complex problem of this kind and must combine different conceptual tools. In view of this, their difficulties are not really surprising. 


\section{The key role of boundary objects}

According to our a priori analysis both the business function and business process methods should play a boundary object role in the transition process between the different learning contexts. These conceptual tools allow the analysis and comparison of different organisations in a homogeneous way as the teacher explained to the students of the 2004 batch.

Excerpt 6 - Students' confusion of function and department (2004 Batch - session 1 $0 \mathrm{~h} 59 \mathrm{~m} 12 \mathrm{~s})$

Teacher (Te): at a certain point in my opinion you started to confuse the notion of business function and the notion of department

St24: yeah

St1: yeah

Te: because gathering the business functions is only a problem of organisational structure all right/ and actually you can gather several business functions in something which is called a department in the company OK / but that's two different things a business function is what must be done to make the company work that's impalpable ((he makes a gesture with his fingers)) only the outcome is concrete all right/ whereas a department is no more than a grouping of physical individuals in one or several rooms there could be some very different departments in a neighbouring company all right / whereas there were the same business functions .. so what did I actually ask you for / what was the aim /

St4: departments

St1-St24: business functions

Te: I asked for the business functions of the company I didn't ask for the departments at a certain point you said this is in the Information Technology department etc. I am not interested in the notion of department but the notion of business function

The business function and business process conceptual approaches should be tools enabling one to translate different contextual realities in a common technical vocabulary, useful for the problem solving space. In this sense, they can be considered as boundary objects, which are key tools in this particular problem. But as we saw previously in our results, the students had great difficulty in using these conceptual tools for the various reasons explained above. Few students had to deal with such organisational issues and the associated tools to manage them. For instance, in 2005, one student (St2) was working in a quality department. He was helping people in the department to set up an ISO 9001 quality management system in the company. One important task was to describe the organisation of the company as different business processes. So this student was supposed to be familiar with this type of tool. The teacher knew that (he was his university trainer) and encouraged him several times. St2 tried to convince the others that this method was useful for the problem solving. However, he had great difficulty in convincing the majority of students to use these complex conceptual tools, all the more because he was not able to master them correctly. He probably lacked a global vision on the complete organisation of a company insofar as he only contributed to one partial aspect of business process modelling. 
This example shows the students' difficulties during their transitions, even when they had previously carried out some work tasks which required the expected concepts. We will see in the next part how the teacher tried to help the students to solve this complex problem, by playing the role of a boundary spanner, which is quite different from a classical teaching role limited to the boundaries of one's academic discipline.

\section{The teacher's role as a boundary spanner}

Previously, we suggested several times the vital role of the teacher in facilitating the students' learning activities. Without this facilitation, they can quickly reach a deadlock in the problem solving. His role and his position are very different from those of a classical teacher: most of the time he stayed in the background. He aimed to let the students manage the problem solving by themselves as much as possible: "I want them to work and take their responsibilities ..." (teacher's interview). At the beginning of each new session, he asked whether one or two students could lead the collective work, and if two others could take the minutes. As he explained to us, he tried to be both in the background and amongst the students: "I often sit in the seat of the student who is at the blackboard" (teacher's interview). This physical changing position has important didactical effects insofar as it shows that the leading role in finding solutions to the problem devolves clearly upon the students. Thus, the teacher's role did not consist mainly in transmitting knowledge but in guiding and regulating the social group's activity. Our hypothesis is that his actions towards the students were attempts to help them in their consequential transitions. In the next paragraphs, we present some frequent types of interventions, which aimed at helping the students in this way.

A first important type of intervention was to give advice to the students about possible previous contexts where they could find some interesting resources.

Excerpt 7 - You already know what a procedure looks like (Batch 2005 - session 1 $0 \mathrm{~h} 37 \mathrm{~m} 51 \mathrm{~s})$

Te: so you all face some information exchanges and I think you have all seen procedures in your company .. in all of your companies there are procedures /

St14: yeah

Te: so you already know what a procedure looks like and how you can manage it /

St6: yeah more or less

Te: more or less OK that's good

St3: we had a lesson on this

Te: yes there was also a very good lesson on this particular point [...] so all that will be useful for you, you will be able to use the very good lessons of our very good teachers ((laughs)) but above all you will use what you have seen in the workplace

In this excerpt, the teacher emphasised the workplace knowledge, but later during the sequence, when the students were discussing solutions for the problem, he tried several times to remind them that they could use some interesting resources from previous teaching units (e.g.: "Te: try to remember your lesson on quality management.. the different levels of a quality system" (batch 2004 - session 1 - 1:14:29)). The teacher also often asked the students about the meaning of a word, a method or a strategy. In the next excerpt, the teacher's first question aimed at checking if all the students understood the notion of business process. The second was designed to provoke a more in-depth discussion between the students about the differences between department and business function. 
Excerpt 8 - What is a business process (Batch 2005 - session $1-0 \mathrm{~h} 59 \mathrm{~m} 32 \mathrm{~s}$ )

Te: is everyone all right with designing the business process / $(7 \mathrm{~s})$

St14: um

St11: um um

Te: ((he sits down on the corner of a table at the back of the classroom)) does everybody understand what designing the business process means /

St8: that's more defining the departments isn't it /

St2: er

St4: the types of production making to order making to stock

St8: the different parts of the company

St2: yeah how we will manage a customer's order (3s) so what do I have to do/ designing...

Te>St8: ((he leans closer to St8)) does it mean the same thing as what you were saying/

St8: yeah yeah well defining the different workstations

As we can see, the teacher's question is pertinent because some students have not understood the real meaning of a business process. Some of them confused this notion with department (St8) or with the types of production (St4). The teacher's questions allowed the students to discover that they did not have the same meaning for this term and opened a debate between them on these different notions. The teacher asked these types of thought-provoking and clarifying questions several times during the two sessions for both the batches.

Another important type of teacher's action is aimed at regulating the social interactions between the students, especially when they quarrel with each other over the best organisation for the Turbix company (c.f. excerpt 7).

Excerpt $\mathrm{n}^{\circ} 7-$ We are not here to fight (batch 2004 - séance $1-1 \mathrm{~h} 01 \mathrm{~m} 18 \mathrm{~s}$ )

(this excerpt immediately follows excerpt 5 )

Te ((sitting down near St23. He turns towards St23 and talks to him in an aside)): we aren't here to fight each other are we /

St23: ha no no

Te: what is really interesting is that you have different experiences in different workplaces the idea here, is to build your own company

St23: yeah yeah

Te: so it's interesting to use what you already know about your company but don't work on the assumption that it's possible to put here in Turbix the organisation of your company

The teacher tried to help the students in their transition from the workplace by explaining the goal is not to stay in the role of an employee defending his own organisation. Instead, it was to move towards a new identity, in a new context and within an emergent community of practice whose aim is to be reflexive, share different experiences and build new types of knowledge. These different types of actions illustrate what the concrete role of a boundary spanner in this type of pedagogical situation may be. This particular teacher can play this type of role because his vocational background allowed him to gain experience in very different contexts. At the beginning of his career, he was a mechanical engineering teacher in a secondary school, but he quickly decided to accept a position at a Technical Institute in a university in the northern part of France. After a number of years, he became the head of a new training course on industrial logistics and quality management (similar to the one in this paper). At this time, he had to teach different academic disciplines because not all the necessary specialists had been recruited. He was also a university trainer in charge of 
following up apprentices in various workplaces. At the same time, he joined the national pedagogical commission, which is in charge of building the reference model of competences and the teaching contents for this diploma (he was still a member of this commission during our study). Several years later, he was recruited by a new technological university institute (his current position) to be responsible for building and maintaining effective working relationships with companies. Thanks to these different experiences, this teacher gained a very good overview of the different learning contexts of the training course and has a horizontal type of expertise, which allows him to cross the boundaries of these different contexts with ease.

However, the teacher seemed to have some difficulty in adjusting his pedagogical strategy in order to use the learning potential of this first part of the sequence The comparison between the two years (Batches 2004 and 2005) shows that he did not manage the class in the same way. In 2004, his strategy was to let the group of students work alone during a first period $(25 \mathrm{mn})$ and, as soon as they reached a deadlock because they were unable to use the useful boundary objects, to then explain their confusion over the different concepts and to take control of the problem solving strategy again until the end of the first step. After this first phase of autonomous work, he was actually the one who initiated most of the next phases of the problem solving and suggested some conceptual tools and how to use them as boundary objects. This strategy explains why there are few discussions about concepts/methods $(\mathrm{K} 2=8.5 \%)$ and problem solving strategy $(\mathrm{K} 1=6 \%)$ for solving the problem. The students only applied what the teacher proposed. Nevertheless, this strategy has the advantage of respecting the time constraints: the first part of the sequence was finished after 2 sessions as initially planned. In 2005, the teacher's strategy consisted mainly in encouraging students (and more particularly one of them, T, see above) to suggest and test different methods and concepts. In this case, he stayed much more in the background, asking for some clarifications and suggesting some more in-depth discussion of some concepts, methods or strategy. Consequently, there was much more discussion of concepts/methods $(\mathrm{K} 2=23 \%)$ and problem solving strategy $(\mathrm{K} 1=18 \%)$ among the students. But the problem solving was not finished after two sessions (students failed to use the concepts and methods correctly) and the teacher had to be more active during the third session as he explained to us during the interview. So, according to the strategy (i.e. the moments and the ways he interacts with the students), the content of discussion between the students can be more or less rich on a cognitive plan. During the interview the teacher admitted that he was still trying to identify the best way to make the greatest learning advantage of this pedagogical sequence. It was probably difficult for him because he lacked the tools (e.g. like our classification) to get objective feedback about the effects of his actions upon the students' activity.

\section{Conclusion}

In this study, we have proposed a theoretical framework for analysing transfer in concrete vocational training courses. Our conceptual approach considers transfer of learning occurs during collateral transitions. Instead of focusing on the cognitive invariants across situations, this approach is interested in the complex changing processes of different types when people cross boundaries between different social contexts. Our research findings show that it is incorrect to always consider transfer as a difficult process, whatever the initial and final learning contexts. In some cases, people can easily use previous knowledge in a new context. But in other situations, transfer of knowledge can be very complex, especially if people are isolated. Understanding what makes transfer complex requires a meticulous examination of what the learning conditions in the previous social contexts were and an analysis of what must be changed in the new context. In this way, some concepts like classification, frame, 
boundary objects, boundary spanners and connectivity can be very useful to analyse the way the pedagogical organisation of educational institutions can either facilitate transfer, transition and knowledge integration or, on the contrary, make them more difficult. They also draw our attention to the very important function of some artefacts and human agents in supporting the transfer process.

Our findings also have practical implications. Vocational training programmes most often include different types of learning contexts, but students are supposed to connect those different learning experiences alone. This kind of segmented pedagogical organisation is based on a liberal view of transfer and learning, which is widely shared amongst policy makers, administrators, teachers and trainers. These different actors of VET systems often believe, more or less consciously, that students are able on their own to take all the possible learning opportunities offered by their different training environments, and then transfer and integrate them to build complex and relevant competences for work situations. Our findings, and those of other studies like Eraut (2004), show this belief is far too optimistic. Students must be supported during their collateral transitions and this problem should be integrated into the design of vocational training courses. The literature in the research field on vocational educational describes different types of activities designed for this purpose (Nielsen, 2009; Onstenk, 2009; Stenström, 2009). In our work, we have analysed the characteristics of one of these possible activities, namely a pedagogical sequence consisting in solving a complex problem requiring various types of knowledge learned previously in different learning contexts. Our results confirm the advantage of this type of pedagogical situation in helping students to connect and integrate their different learning experiences. Our findings also highlight the key role of the teacher, in both the design and the management of these situations. The teacher first had to build the complex problem, requiring different types of disciplinary knowledge, and some practical experiences to solve it. Then, during the class sessions, he had to regularly decide whether he should stay in the background or intervene with the students, to orient, encourage, correct, etc. Regular teachers, only experts in one or a limited number of discipline(s) can have great difficulties in building and managing such complex problem solving situations, insofar as they require a detailed knowledge of the content of the different learning contexts. Developing this type of pedagogical activity requires some changes both in the teacher training programmes (initial and continuing) and in the pedagogical organisation of VET courses. For instance, it might be helpful to use videorecordings like those we obtained to illustrate the students' difficulties in adapting and applying previous knowledge in a new learning context. This would also allow students to analyse different types of teacher's interventions and pedagogical strategies and their effect on the students' activity. More generally, it would be interesting to add some content about students' collateral transitions to teacher training programmes, including methodological approaches to the design of appropriate situations or activities. One key idea of this content would be the notion of collaborative design, that is the preparation of the pedagogical settings in close collaboration with the entire pedagogical team (including the teachers and trainers in the workplace), to create connexions between the different teaching units and the workplace activities. Moreover, as described above, this type of situation remains difficult to manage, even for an experienced teacher with strong horizontal expertise. Practitioners lack serious feedback on the effects on the students' activity and learning of their different types of action and interaction. More research must be undertaken in order to identify training strategies offering the best learning opportunities.

\section{Transcription conventions}

/ raising intonation

. pause lasting less than $1 \mathrm{~s}$ 
.. pause lasting between 1 and $2 \mathrm{~s}$

$>$ addressor-addressee relation $(\mathrm{Te}>\mathrm{St} 8)$

((comments)) comments regarding non verbal behaviour

$[\ldots]$ speech cut out (by the researcher for editorial purposes in this paper)

\section{References}

Anderson, J. R. (1983). The architecture of cognition. Cambridge, MA: Harvard University Press.

Baldwin, T. T., \& Ford, J. K. (1988). Transfer of training: a review and directions for future research. Personal psychology, 41, 63-105.

Beach, K. (1999). Consequential Transitions: A Sociocultural Expedition Beyond Transfer in Education. Review of Research in Education, 24, 101-139.

Bereiter, C. (2002). Education and mind in the knowledge age. Mahwah, NJ: Erlbaum.

Bereiter, C., \& Scardamalia, M. (1993). Surpassing ourselves: An inquiry into the nature and implications of expertise. La Salle, IL: Open Court.

Bernstein, B. (1996). Pedagogy, symbolic control and identity. Theory, Research, Critique. London: Taylor \& Francis.

Billett, S. (1994). Authenticity in workplace learning settings. In J. C. Stevenson (Ed.), Cognition at work: the development of vocational expertise (pp. 36-75).

Billett, S. (2001). Learning in the Workplace: Strategies for Effective Practice. Crows Nest NSW: Allen \& Unwin Academic.

Bransford, J. D., \& Schwartz, D. L. (1999). Rethinking transfer: a simple proposal with multiples implications. Review of research in education, Chapter 3, Vol.24, 61-100.

Buxton, C. A., Carlone, H. B., \& Carlone, D. (2005). Boundary spanners as bridges of student and school discourses in an urban science and mathematics high school. . School Science and Mathematics, 105(6), 302-312.

Detterman, D. K. (1993). The case for the prosecution: transfer as an epiphenomenon. In D. K. Detterman \& R. Sternberg (Eds.), Transfer on trial: intelligence, cognition and instruction (pp. 1-24). Norwood: N.J.: Ablex Publishing Corporation.

Detterman, D. K., \& Sternberg, R. J. (Eds.). (1993). Transfer on trial: intelligence, cognition and instruction. Norwood NJ: Ablex.

Engeström, Y. (1987). Learning by expanding : an activity-theoretical approach to developmental research. Helsinki: University of Helsinki.

Engeström, Y., Engeström, Y., \& Kärkkäinen, Y. (1995). Polycontextuality and boundary crossing in expert cognition: learning and problem solving in complex work activities. Learning and Instruction, 5, 319-336.

Eraut, M. (2004). Transfer of knowledge between education and workplace settings. In H. Rainbird, A. Fuller \& A. Munro (Eds.), Workplace learning in context (pp. 201-221). London: Routledge.

Frenay, M. (2004). Du transfert des apprentissages au transfert de connaissances. In A. Presseau \& M. Frenay (Eds.), Le transfert des apprentissages: comprendre pour mieux intervenir (pp. 7-48). Québec: Presses Universitaires de Laval.

Fuller, A., Hodkinson, H., Hodkinson, P., \& Unwin, L. (2005). Learning as peripheral participation in communities of practice: a reassessment of key concepts in Wokplace Learning British Educational Research Journal, 31(1), 49-68.

Gibson, J. (1979). The Ecological Approach to Visual Perception. Boston: Houghton Mifflin.

Greeno, J. G., Smith, D. R., \& Moore, J. L. (1993). Transfer of situated learning. In D. K. Detterman \& R. J. Sternberg (Eds.), Transfer on trial: intelligence, cognition and instruction. Norwood, NJ: Ablex. 
Griffiths, T., \& Guile, D. (2003). A connective model of learning: the implications for work process knowledge. European Educational Research Journal, 2(1), 56-73.

Hughes, K. L., \& Moore, D. T. (1999). Pedagogical strategies for work-based learning. NewYork: Institute on Education and the Economy.

Konkola, R., Tuomi-Gröhn, T., Lambert, P., \& Ludvigsen, S. (2007). Promoting learning and transfer between school and workplace. Journal of Education and Work, 20:3, 211228.

Koskinen, K. U. (2008). Boundary brokering as a promoting factor in competence sharing in a project work context. , International Journal of Project Organisation and Management, 1(1), 119-132.

Lave, J. (1988). Cognition in practice, Mind, Mathematics and culture in everyday life. Cambridge: Cambridge University Press.

Lave, J., \& Wenger, E. (1991). Situated Learning : legitimate peripheral participation. Cambridge: Cambridge University Press.

Leinhard, G., McCarthy Young, K., \& Merriman, J. (1995). Integrating professional knowledge: the theory of practice and the practice of theory. Learning and Instruction, $5,401-408$.

Lorino, P. (1995). Comptes et récits de la performance. Essai sur le pilotage de l'entreprise. Paris: Les éditions d'organisation.

Nielsen, K. (2009). A collaborative perspective on learning transfer. Journal of Workplace Learning, 21(1), 58-70.

Nonaka, I., \& Takeuchi, H. (1995 ). The Knowledge-Creating Company. Oxford: Oxford University Press.

Onstenk, J. (2009). Connections of school and work-based-Learning in the Netherlands. In M. L. Stenström \& T. Y. (Eds.), Towards integration of work and learning. Strategies for connectivity and transformation (pp. 187-199). New-York: Springer.

Pastré, P. (2008). Apprentissage et activité. In Y. Lenoir \& P. Pastré (Eds.), Didactique professionnelle et didactiques disciplinaires en débat (pp. 53-79). Toulouse: Octarès éditions.

Reed, S. K. (1996). A schema-based theory of transfer. In D. K. Detterman \& R. J. Sternberg (Eds.), Transfer on trial: intelligence, cognition and instruction (pp. 39-67). Norwood, N.J.: Ablex Publishing corporation.

Rosch, E. (1977). Human categorization. In N. Warren (Ed.), Advances in cross-cultural psychology (Vol. 1). London: Academic Press.

Samurçay, R., \& Rabardel, P. (2004). Modèles pour l'analyse de l'activité et des compétences : propositions. In R. Samurçay \& P. Pastré (Eds.), Recherches en didactique professionnelle (pp. 163-180). Toulouse: Octarès Editions.

Schank, R. C., \& Abelson, R. P. (1977). Scripts, Plans, Goals and Understanding: an Inquiry into Human Knowledge Structures. Hillsdale, NJ: Erlbaum.

Scribner, S. (1985). Knowledge at Work. Anthropology \& Education Quarterly, 16(3), 199206.

Shulman, L. S. (1986). Those who understand: knowledge growth in teaching. Educational Researcher, 15(2), 4-14.

Senström, M.-L., \& Tynjälä, P. (Eds.). (2009). Towards integration of work and learning. Strategy for connectivity and transformation. New York: Springer.

Simon, H. A., \& Chase, W. G. (1973). Skill in chess. American Scientist, 61, 394-403.

Singley, M. K., \& Anderson, J. R. (1989). The transfer of cognitive skill. Cambridge, M.A.: Harvard University Press. 
Star, S. L., \& Griesemer, J. R. (1989). Institutional ecology, "translations" and boundary objects: Amateurs and professionals in Berkley's Museum of Vertebrate zoology, 1907-1939. Social Studies of Science, 19(387-420).

Stenström, M. L. (2009). Connecting work and learning through demonstrations of vocational skills. Experiences from the Finnish VET. . In M. L. Stenström \& T. Y. (Eds.), Towards integration of work and learning. Strategies for connectivity and transformation (pp. 221-238). New-York: Springer.

Tanggaard, L. (2008). Learning at School and Work: Boundary crossing, strangeness and legitimacy in apprentices' everyday life. In V. Aarkrog \& C. H. Jorgensen (Eds.), Divergence and convergence in education and work (pp. 219-237). Bern: Peter Lang.

Thorndike, E. L., \& Woodworth, R. S. (1901). The influence of improvement in one mental function upon the efficacy of other functions. . Psychological Review, 8, 247-261.

Tuomi-Grohn, T., \& Engeström, Y. (2003). Conceptualizing transfer: from standard notions to developmental perspectives. In T. Tuomi-Grohn \& Y. Engeström (Eds.), Bewteen school and work: new perspectives on transfer and boundary crossing (pp. 1-14). Oxford: Elsevier.

Tynjälä, P. (2009). Connectivity and transformation in work-related learning. Theoretical fundations. In M.-L. Stenström \& P. Tynjälä (Eds.), Towards integration of work and learning. Strategies for connectivity and transformation (pp. 11-37). New-York: Springer.

Veillard, L., \& Coppé, S. (2009). Mobilisation de connaissances antérieures en formation professionnelle par alternance : perspectives apportées par une approche comparatiste. Education et Didactique, 3(2), 47-80.

Volanen, M., V. (2009). Being, doing, making. A paradigm for the connective curriculum. In M. L. Stenström \& P. Tynjälä (Eds.), Towards integration of work and learning. Strategy for connectivity and transformation (pp. 39-59). New York: Springer.

Wenger, E. (1998). Communities of practice: Language, learning, and meaning. Cambridge: Cambridge University Press. 